\title{
Let the Invisible Be Visible and the Unheard Be Heard Public Art and Social Action
}

\begin{abstract}
XieYong ${ }^{1, *}$
${ }^{1}$ Fine Art \& Design Academy, ShenYang University

Email:17418576@qq.com

ABSTRACT

Through public arts and my artistic practice to explore how art practice actively contributes to raising civic awareness around issues of social concern in contemporary China. I argue for their contribution to the field of public sculpture in China. The case studies will unpack the research process and highlight the aspects of the work that challenge conventions in public sculpture in China. They will also draw out the impact of the work with audiences, particularly how media engagement has extended the discourse around the sculptures, disseminating that art can be a powerful vehicle to communicate and interact with the public on subjects that are difficult and complex in China. My aim, is at a minimum, to raise social awareness and spark debate in as wide an audience as possible. Ideally, I would want to see the artworks impact on social change and contribute meaningfully to creating a respectful society.
\end{abstract}

Keywords: public arts, social concern, civic awareness, interact

\section{INTRODUCTION}

Since the political reform and opening up of China internationally in the 1980 s, China's society has undergone tremendous changes that saw the economy developing rapidly. This change is not only a change in material wealth, but also an all-round change from an emphasis on cultural tradition to a humanistic and individual spirit with a subsequent shift in social values. In parallel to this dramatic change in Chinese society, an increasing number of artists have been responding to concerns about social situations and societal challenges. Until recently, this approach has been at odds with international perspectives on art and society. Progressive artists in China have begun to express their individual attitudes and viewpoints through their art, in an attempt to trigger changes in public thinking and understanding.

Arthur Clive Heward Bell was an English art critic. In the last chapter "The Future" of his book "ART"published in 1913, he elaborated on this view: "It is a mistake to suppose that because society can not affect art directly, it cannot affect it at all. Society can affect art indirectly because it can affect artists directly." The expansion of contemporary art, where engagement with life and popular culture, indicates that artists shifted from a focus on the individualized pursuit of modernism to one paying more attention to communication and interaction between people and society [1].

Interaction is not only the result of crossover, but also the change of artistic personality, that is to say, artists no longer regard themselves as self-evident and omnipotent aesthetic revolutionaries imposing artistic creation on society, but present their feelings and experiences of society, history, life and existence with an open mind. In an international art context, especially since the 1990s, there has also been a new trend in the art world; artists, curators and critics have jointly sought the combination of society and art to create, produce and implement contemporary art (works). 1 This invisibly promotes art to be more closely connected with society. The art of cooperation, participation and intervention has emerged. This is in line with eliminating the barriers and boundaries between art and life (society). It transcends formalism and enters the field of cooperative dialogue in civil society.

In China, with the expansive impact of economic development, political and social changes are gradually becoming embedded in civil society. This participatory function of art is embodied in the way of contemporary art, showing a new type of artistic relationship different from the past, that is, the relationship of art intervening 
in society. It coincides with the current development of world art and also shows the sensitivity and responsibility of Chinese artists. In the visible future of China, China does not lack the aesthetic art of formalism and propaganda, the art of dogma, but lacks the free expression of artists from independent thinking and critical spirit. To interpret free expression, this type of thinking is a positive mode of intervention. It tries to expand the function of art and give it a new expressive function and a value that extends beyond traditional Chinese artistic models. What has been lacking is the space and opportunity for Chinese artists to express their independent critical and reflective spirit. The work emerging from this more individualized, subjective approach, produces art that is quite unique in the Chinese context. And as it becomes embedded in the current context of China, it provides a cultural and critical vehicle for artists to communicate a sense of the times and challenges facing the Chinese people.

Art intervention as an active action is a manifestation of the individual's self-consciousness. It has a strong reflective attitude. If it does not appear as an independent individual, its micro-individual perspective will not be reflected. Therefore, it is impossible to show that art is the artist's art, not a collective art.

As an artist who has experienced this unprecedented change in Chinese society, I truly understand people's spiritual confusion, anxiety and conflict brought by this great change, as well as the contradictions at all levels of society. I choose to use my own art language combining with my survival experience, to present my personal attitude, expression and reflection. I use my work to touch the "pain point" of society, bringing the audience back to social reality and triggering discussions and reflections. This shift from a collective consciousness in Chinese culture, to an individualized experience, has been a powerful catalyst for me, providing the opportunity to explore and communicate universal issues arising from individual experience.

From the works of the Chinese artists who pay attention to social and political issues, such as $\mathrm{Xu}$ Bing, Cai Guoqiang, we can see the artists' consciousness and concern for society and the influence and changes on civic awareness and the political environment. They experienced the Cultural Revolution first hand during their youth and embodied that experience in their art. Collectively, although quite diverse in their individual practice, each artist exemplifies the powerful impact of the socio-political upheaval which transformed nearly all aspects of Chinese culture. They also represent the widespread diaspora of contemporary artists from China in the late-20th century, who sought artistic freedom during a period of censure in their home country. Unlike them, who have focused on political radicalism, my inspiration comes from the reality of lived experience, my experience. The purpose of my art is to create dialogue, interact, influence society and promote some moderate change. They are more personal than political, and although might engage themes familiar in a Western context, they draw attention to the subject, and issues in Chinese society that are invisible and not well recognized or understood.

Since 2005, I have been investigating, through my art, aspects of social reality in China. This has led me to focus on a range of issues, including animal protection, teenage mental health and the online safety and bullying of children. I have created a series of projects and exhibited them in public spaces, in order to engage with a wide public. The main characteristics of my art can be summarized as follows.

\section{THEME}

In the dramatic changes to the political landscape and associated economic reform over the past 40 years, China's reality is undoubtedly become more complex and has more aspects to explore. Urbanization, capital monopoly, the gap between the rich and the poor, social equity and the improvement of the legal system are all specific issues arising from social change. Even democracy has different specific demands in China's society. my art practice pays more attention to exploring the relationship between people and the society, the research, analysis and display of people's multiple spiritual worlds, the presentation of old and new values, and the cultural conflict between the east and west. I speak for the week and give a voice to the silent through my art, including children, animals, the disabled.

Jacques Rancière: "Good art must negotiate the tension that (on the one hand) pushes art towards 'life' and that (on the other) separates aesthetic sensorially from other forms of sensible experience." In the process of creation, by constantly experimenting with and exploring new artistic language, I display the concepts in the most appropriate artistic form, material and media. "Let the invisible be visible and the unheard be heard". I have developed my own unique art language through the practice. Unlike the rhetorical, political and oppressive language of propaganda seen in Chinese sculptures from the past. I emphasize a more grounded reflection from current life, the real feelings, emotions and demands of ordinary people, especially those who are weak and have no voice, recording and expressing the times.

\section{EXHIBITION -INTERACTION WITH AUDIENCE}

The relationship between my work, audience and the venue are no longer the one between the subject and the object, but a multi-dimensional interaction, influencing and affecting each other. Unlike traditional art galleries and museums, which emphasize the academic and artistic 
nature of artworks, I choose open spaces such as city shopping malls and commercial centers to exhibit my works. This allows me to develop direct dialogue with the public, highlighting the social and humanistic value of my works while allowing the concept of the work to be widely disseminated and discussed through the internet, social media etc. The purpose is to effectively interact and intervene in social reality. This is a choice that stems from my strong responsibility and desire for art to contribute to the creation of a better society [2].

I will use case studies of public art in China. These projects discuss the social problems in China, but not only limited in China, they are the global challenges for all of us. The projects demonstrate my attitudes and actions, as an artist actively engaging in society. These projects have been widely recognized and discussed by the public, because of the original art language and materials I developed and the impact on the audience. We have seen the changes on the people's behaviors and Chinese society. The case studies will unpack the research process and highlight the aspects of the work that challenge conventions in public sculpture in China. I will also draw out the impact of the work with audiences, particularly how media engagement has extended the discourse around the sculptures, disseminating my ideas to a wider public.

\section{PUBLIC ART WORK-WORDS CAN BE WEAPONS}

Social Context: The initial research enquiry considered the term language violence, particularly in the context of Chinese culture. The term refers to the use of abusive, slanderous, contemptuous, ridiculous and other insulting discriminatory language, resulting in mental and psychological violations and damage to others. The victims of language violence are often children or young people. In many cases, the violence, usually in verbal form but increasingly text based via social media, originates from unequal interrelationships. Victims usually lack the power to defend themselves. Clearly, the language violence suffered by minors falls into this category.

In Chinese society, children's education is prioritized by families and is prioritized in a culture where parents have been limited to having one child. Parents have extraordinarily high expectations for their children, and they often get "angry because their children's performance does not meet their unreasonably high expectations. For this reason, the phenomenon of "language violence" in the communication with children within the family, is sometimes accompanied by corporal punishment, beating and scolding, and other irrational acts. We often hear some parents say to their children: Stupid, Lame duck! All you do is eat! You are a disgrace! Why don't you go die! Stupid brain! and so on.
This form of domestic violence is considered harmful to children's psychological growth. Firstly, it attacks children's self-confidence leading to feelings of inadequacy in relation to their peers; secondly, it will make children feel an absence of love within the family, resulting in negative responses, including a rebellious psychology; additionally, this can even effect children's interpersonal communication, leading to autistic behavior. "Language violence" will cast a shadow on children's young hearts, the wounds in childhood will continue to worsen and magnify, which may eventually push children from feelings of inferiority to more extreme response, including criminal acts.

Professor Jiang Junhe of Shenyang Institute of Psychology well-known children psychologist in China, pointed out that: Parent's language is an external stimulus to their children. If children feel their parents' language a blow and a injury to themselves, they will not want to make progress and their grades are getting worse and worse. When a child is evaluated by their parents' insulting language, he will tend to produce wrong consciousness, doubting his learning ability, and denying his self-worth, thus giving up on himself [3]. According to the results of the survey Prof Jiang did, $80.3 \%$ of the children who suffer verbal abuse showed a loss of interest in their studies, which in some cases lead to drop out of school. Professor Zheng Liandi, "that children who have been exposed to verbal abuse for a long time are prone to two negative personalities: retreating personality and an attacking personality. Children who are often verbally abused by their parents, lack security, love and the feeling of belonging, and are without self-confidence. Negative emotions have been accumulating in their hearts. The children will become nervous and anxious. Introverted children tend to form this retreating personality, and are timid with low self-esteem, disguising themselves, which influences their communication and interaction with peers. On the other hand, adolescents who have long experienced verbal abuse, with psychologically negative emotions accumulating, will eventually form violent thinking and a attacking personality, which affect interpersonal relationships, in some serious cases developing into criminal behavior."

This kind of verbal abuse can be seen everywhere in daily life. Parents and teachers consider their "violent language" as a form of concern and care for children, regardless of their children's psychological feelings. People mostly recognize and pay attention to the impact of physical violence, but the harm of language violence, especially in a domestic environment, is rarely discussed by Chinese society. Some words that parents said to their children may impact them beyond the incident, with children carrying the hurt into their adult life. The project conceives this violent language as a form of weapon. A weapon, invisible, yet as powerful as any physical weapon. Although it does not leave any physical scar on 
the child's body, it leaves trauma in their hearts that is difficult to erase.

\section{INSPIRATION AND INSIGHT}

The social reality of situations is my primary stimulus. Much of my creative inspiration and passion emerges from lived experience and it is the interaction with people during my initial research, which provides me with the materials and motivations to create. In China, legal sanctions and moral criticism have lagged behind other countries with serious consequences for long-term verbal violence on children. Art practice has an advantage over other communication media in that the visualization, intuition, image, and authenticity of the artwork are appealing to audiences. By transforming abstract social phenomena into visual, accessible and clear artistic works of art. One of the key reasons for this social issue is the universal barrier of communication and interaction between parents and children. Taking this as a breakthrough point, I utilize the daily interactive game between adults and children as a medium to present my work, showing the fact that violent language can cause cumulative harm to children by visualizing the modeling conversion of the artwork. At the same time, parents and children will be invited to participate in the interactive presentation of the project, and jointly complete the exhibition of "Words Can Be Weapons"[4]

This approach is a key touchstone for my own practice. Recognizing that difficult situations and cultural norms are hard to interrogate and communicate. Art practice is perfectly situated to respond to the challenge. Particularly outside of the art gallery where the artwork can engage a wide audience.

Primary Interviews with juvenile offenders at Prison. From October 2013 to December 2013, I visited local Prison three times with Professor Jiang Jun, Director of the Institute of Psychology, and interviewed 11 juvenile offenders serving their sentences. The purpose is to communicate with offenders who committed crimes due to emotional impulse or negligence, to understand the relationship between their criminal actions and long-term family verbal abuse.

The concept of the project is involved in three questions: 1. How to present invisibility of "language violence" by a visible art form? 2. How to realize the idea that "violent words" is the same as "weapons" for children? 3. How to get audience involved in and spark a dialogue around the subject? The research and interviews showed me the emotional and psychological hurts brought by language violence, which is not considered a weapon, but much stronger than real physical weapons. This realization inspired me to make weapon of words as my visual language to show the pains and harms and talk to the public.
Identify creative elements and materials: "violent language" and "violent weapon". Collecting and confirming the most used violent words through questionnaires, surveys, interviews etc. as the following: idiot, you are a disgrace, anyone is better than you, all you know is eat, why don't you go die, garbage, and other high-frequency words and phrases. At the same time, sorting out the important tools and weapons used in many criminal cases: knives, axes, guns, daggers and other criminal weapons.

Design the artistic expression and presentation from "word" to "lethal weapon". The idea is to utilize the similarity between the shape features of Chinese characters' strokes and the structure of weapons to design the transformation. To restore the weapons of crime, I find the similarity between strokes of Chinese characters and constructions of the weapons, then select materials and techniques that are close to the real lethal weapon to present the idea.

\section{DESIGN THE CONNECTING STRUCTURE}

Exhibition-Interaction between the artworks and audiences in public space. On April 1, 2014, the exhibition of "Words can be weapons" was held as scheduled in the first-floor lobby of Sunshine Department Store in the center of Shenyang. A week before the exhibition, I had invited 20 groups of parents and children to take part in the exhibition and interaction online through social media, to help complete the final presentation of the project.

Interaction with audiences online - Dissemination of the concept is an integral part of the work and the completion of the project. I extended the interaction of "refusing verbal abuse" online and opened a consulting corner on an official website of Shenyang Institute of Psychology. Here people could participate in online discussion. The audience could be connected with a child psychologist and therapists online, enabling them to answer relevant questions and give professional advice.

Dissemination and Social Impact- This exhibition both in public space and online had great impact and a clear influence on public opinion. The project made headlines of the mainstream media from the first day of the exhibition. In the following years after the exhibition, the events, TV special reports, government media coverage, seminars and discussions relating to "refuse verbal violence" in Chinese society have continued and become the focus of social attention, especially verbal abuse on children in family and at school [5].

\section{CONCLUSION}

Responding to changes in public opinion, China's first "Anti-Domestic Violence Law" was formally 
promulgated in March 2016, in which the definition of domestic violence was clearly defined: "It refers to physical and mental violations committed by family members by means of beating, binding, maiming and other restrictions on personal freedom, as well as frequent verbal abuse and intimidation." The promulgation of this anti-domestic violence law proves that the interaction between art and social action can have a positive impact on the development of society.

As an artist, I hope art work is not only been seen by as many people as possible, but engaged deep and wide in society to make change. By all these public engagements of my project, I want to sew seed of changes in people's behaviors and thoughts.

\section{REFERENCES}

[1] Bishop. C., (2012) Artificial Hell: Participatory Art and The Politics of Spectatorship. London Verso, pp29-30.
[2] Casarosa, F., (2008) Child Protection Online: Uneasy Steps towards a Balance between Risks and Freedoms Eur. J. European Journal of Legal Studies, Vol. 2, Issue 3 (2010), pp. 80-94

[3] Skellern C., (2021) Thinking fast and slow in the evaluation of injury plausibility in child protection. J. Journal of Forensic \& Legal Medicine. Vol 53, Issue S1. PP S8-S9.

[4] Hajo.N., (1998) Cyber Cites: Visual Perception in the Age of Electronic communication (review). J. Technology and Culture, Vol 39, Issue 3. PP 598600

[5] Jiang Z et al., (2021) The art of labour organizing: participatory art and migrant domestic workers' self-organizing in London. J. Human Relations, Vol 74, Issue 6. PP 842-868 